\title{
The Role of Physical Education Homework to Adolescent Girls' Physical Activity in Finland
}

\author{
Mari Kääpä1* ${ }^{*}$, Sanna Palomäki', Henri Vähä-Ypyä², Tommi Vasankari², Mirja Hirvensalo1 \\ ${ }^{1}$ Faculty of Sport and Health Sciences, University of Jyväskylä, Jyväskylä, Finland \\ ${ }^{2}$ UKK Institute Promoting Health-Enhancing Physical Activity, Tampere, Finland \\ Email: ^mari.p.kaapa@jyu.fi, sanna.h.palomaki@jyu.fi, henri.vaha-ypya@uta.fi,tommi.vasankari@uta.fi,mirja.hirvensalo@jyu.fi
}

How to cite this paper: Kääpä, M., $\mathrm{Pa}$ lomäki, S., Vähä-Ypyä, H., Vasankari, T., \& Hirvensalo, M. (2019). The Role of Physical Education Homework to Adolescent Girls' Physical Activity in Finland. Advances in Physical Education, 9, 223-239.

https://doi.org/10.4236/ape.2019.94016

Received: August 15, 2019

Accepted: October 7, 2019

Published: October 10, 2019

Copyright (C) 2019 by author(s) and Scientific Research Publishing Inc. This work is licensed under the Creative Commons Attribution International License (CC BY 4.0).

http://creativecommons.org/licenses/by/4.0/

\section{Abstract}

Introduction: There is an urgent need for active strategies to promote physical activity (PA) among female adolescents, as they are at greater risk of physical inactivity. In addition to Physical Education (PE) in school, to reach adequate levels of PA, young people need to participate in PA during the school day and/or after-school hours and/or in the before-school period. One week of objectively measured and self-reported information enlightens the status quo of adolescent girls' PA and the role that PE homework plays. Purpose: The purpose of this study was to examine girls' objectively measured PA in a lower secondary school as part of the Physical Education Homework Study, a project conducted in Finland. An additional aim was to provide insights into physical education (PE) homework as part of PA. Methods: Different levels of PA (i.e., light, moderate, vigorous), sedentary time, number of total steps and running steps were measured using accelerometers among girls in the 7th, 8th and 9th grades, aged between 12 and 15 years $(n=88)$ for a period of 1 week. In addition, self-reported structured diaries were used to gather information about after school activities, including PE homework. An analysis of variance (ANOVA) and Tamhane's post-hoc test was used to compare the different grades on the basis of participants' PA levels and sedentary time. Data from self-reported PE homework frequencies and time spent on PE homework were analysed using the independent-samples t-test. Results: The PE homework was a small aspect of the participants' whole-day PA, averaging 34 minutes per week (7th grade girls 20 minutes, 8th grade girls 51 minutes, and 9th grade girls 32 minutes). Half of the girls from the 8th grade reached the 60 -minute PA recommendation every day; $38 \%$ of all the girls met the recommended levels of PA. For the 7th grade girls, 35\% met the recommendation, while $28 \%$ of the 9th grade girls reached the PA guidelines. The 7th grade girls recorded an average daily light PA time of 3 hours 28 minutes; this was 34 minutes more than the girls from 8th grade ( $p=$ 
$0.000)$ and 30 minutes more than the girls from the 9th grade $(p=0.000)$. Conclusion: The PE homework provided a variety of PA for the adolescent girls' after-school hours, even if the role of homework was not time-consuming (20 - 51 minutes per week). A possible way of promoting active time among adolescents during after-school hours is to assign them PE homework, hence, active PE assignments could replace sedentary activities in adolescent girls' lives.

\section{Keywords}

Physical Activity, Adolescent Girls, PE Homework, Accelerometer, Self-Report

\section{Introduction}

In most countries, physical activity (PA) participation radically decreases during lower secondary school, especially among girls (Currie et al., 2008: pp. 105-107; Ekelund et al., 2012; Haapala et al., 2017). As a result, many adolescents fail to meet the recommended levels of PA (Currie et al., 2008; Pate \& O'Neill, 2009; Husu, Vähä-Ypyä, \& Vasankari, 2016). According to the Finnish National Physical Activity Recommendations, adolescents should be physically active more than 60 minutes per day (Tammelin \& Karvinen, 2008). In Finland, only 10\% $17 \%$ of adolescents aged between 13 and 15 attain moderate-to-vigorous levels of PA, with the most radical decline in PA occurring among girls aged between 11 and 15, in their transition from childhood to adolescence (Kokko et al., 2015; Tammelin, Laine, \& Turpeinen, 2013). According to Pate \& O'Neill (2009), the objectively measured PA of adolescent girls declines at a rate of approximately $4 \%$ annually. This means that with time, the level of PA among girls recedes further from current PA guidelines.

Nearly half of young people's total daily PA accumulates after school, although the levels of after-school activity start to decrease gradually during preadolescence, while sedentary exposure increases as early as ages 9 to 11 (Wickel, Issartel, \& Belton, 2013). Since female adolescents seem to be at greater risk of physical inactivity, there is an urgent need for effective strategies to promote PA among them (Aelterman et al., 2012). The after-school period represents a segment of the day in which adolescents' health-enhancing levels of PA should be promoted (Beets et al., 2009). However, adolescents, particularly girls, accumulate low levels of moderate-to-vigorous physical activity (MVPA) during after-school hours, and their MVPA levels decline at a faster rate (Okely et al., 2011; Pate \& O’Neill, 2009). According to Atkin et al. (2008), technology-based sedentary behaviour is the most prevalent activity among adolescents in after-school hours; the sedentary time of girls lasted for 35 minutes per day. Meanwhile, the times spent physically active amounted to 19 minutes for girls per day (Atkin et al., 2008). 
School is an important institution for PA promotion, as the vast majority of youths attend school. Thus, physical education (PE), as a structured school activity, has great potential in terms of public-health reach (Scruggs, 2007). There have been calls for schools to expand their efforts to increase PA-related opportunities to obtain higher levels of PA in adolescents, particularly adolescent girls. Even if school PE lessons are well organized and PA levels during these lessons are adequate, PE lessons do not exert a sufficient influence over adolescents' PA and health (Fairclough \& Stratton, 2005). MVPA is performed most often during leisure time, while school sports contribute only marginally to MVPA (Pfitzner et al., 2013). In Finland, a great deal of effort has been set into activating school days, for example, the Finnish Schools on the Move (Haapala et al., 2017). In addition to school PE, to reach adequate levels of PA, children and young people need to participate in PA during the school day and/or during after-school hours and/or in the before-school period. A possible way of promoting PA among youths is to assign PE homework (Gabbei \& Hamrick, 2001; Williams \& Hannon, 2013; Kääpä et al., 2017). Homework assignments could be designed to practise activities learned earlier at school; to be effective, the practicing should take place during after-school hours. Physical homework provides an opportunity for students to apply and practice the skills learnt in PE lessons (Gabbei \& Hamrick, 2001; Williams \& Hannon, 2013). According to Kääpä et al. (2017), students can find PE homework enjoyable and beneficial. For example, students enjoyed PE homework that included practicing with family member. In addition, it has been found that Finnish students enjoy participating in planning PE homework (Kääpä et al., 2017). The Finnish National Core Curriculum allows and even encourages the use of leisure time to practice skills learnt during lessons (Finnish National Core Curriculum, 2014). PE homework assignments can be implemented in nearby sporting environments or facilities. Becoming familiar with the physical environment and facilities while undertaking PE homework helps to make PA part of one's lifestyle (Williams \& Hannon, 2013; Smith \& Claxton, 2003).

The purpose of this study was to examine the objectively measured PA levels of adolescent girls in a lower secondary school in Finland and provide insights into the role of PE homework as part of adolescent girls' PA. The participants' MVPA, sedentary time, and the number of total steps and running steps were reported, and compared to PE homework-participation. Using both types of steps and the MET values add variety and reliability to the results and enable comparison between the step-based studies as well.

\section{Materials and Methods}

\subsection{Design of the Study}

This study is part of the Physical Education Homework Study, a project that began in Finland in 2015. The purpose of the study was to attempt to increase adolescents' PA time by giving them active PE homework during PE lessons (Kääpä 
et al., 2017). This week-long cross-sectional study, conducted in autumn 2016, concentrated on gathering information about adolescent girls' PA and the role of PE homework by using objective measurements and self-reported methods.

\subsection{Participants}

The participants for this study were girls in the 7th, 8th and 9th grades in a lower secondary school in central Finland. The girls were aged between 12 and 15 years. The half of the girls live near the school and half of them commute to school by buss. From a total of 124 girls, 105 (84.7\%) agreed to participate in the study. Girls and their parents were informed about the study beforehand, and informed consent was obtained from the parents/guardians. According to the layer of the University Ethical Board, this protocol covers needed ethical permissions concerning this type of research. The study consisted of week-long objective PA measures using accelerometers and structured self-report diaries during the measurement week. There were missing data from 17 participants as a result of students (12) who were absent from school during the measurement week, and some accelerometer problems that were encountered. The actual study data consists of information from participants who had at least 4 days of accelerometer data $(n=88)$ and questionnaires concerning their self-report diaries $(n=81)$. In self-reported data, the division was 28 girls from the 7 th grade, 26 girls from the 8th grade and 27 girls from 9th grade. In the objectively measured data analysis, to get the most comprehensive overview about the adolescents' physical activity, all of the participants acceptable (at least 4 days, $10 \mathrm{~h}$ minimum/day) accelerometer data were used $(n=513)$. For this reason, the measurement days consisted of 190 days of data from the 7th grade girls, 152 days of data from the 8th grade girls and 171 days of data from the 9th grade girls. Girls' who had both objectively measured and self-reported data were included in analyses of compound measurement results (No PE homework $n=238$, PE homework twice a week or more $n=248$ ).

\subsection{Setting}

In Finland, the school day usually begins at 8:00 am and ends at 3:00 or 4:00 pm. The normal school-day structure consists of 7 to 8 lessons lasting for 45-minute each, with a 15-minute break between the lessons and a 30-minute lunch break at noon. The Finnish Schools on the Move program has concentrated on activating students during the school day and using the breaks in an active way (Haapala et al., 2017). The PE Homework Study focuses on activating after-school hours (Kääpä et al., 2017). During the study period, the lower secondary school students had $2 \times 45$ mins PE lessons in a row (lasting 90 minutes) once a week. In Finland, this double classes one day a week is normal national standard. In Finland, organized after-school sport activities for adolescents usually take place in sport clubs and in teams. According to Blomqvist et al. (2015), over half (53\%) of the Finns in their study aged between 9 and 15 took 
part in sports-club activities at least once a week. Their participation declined as they aged, with low levels of participation among 15-year-old (Blomqvist et al., 2015).

The PE teacher (first author) had occasionally given the girls in the lower secondary school PE homework in past years; thus, the concept of PE homework was familiar to them. PE homework was an aspect of PE that was undertaken by all of the girls. Homework assignments followed PE requirements, and they were given to all students in every PE lesson once a week during the study year. This meant that PE homework was given between 30 and 40 times per school year. PE homework assignments often consisted of body-conditioning exercises such as push-ups, squats or ab crunches; jogging with a family member or friend; stretching; or some skill or activity from the PE lesson. An example of PE homework is balance practices, where the student stands on their right foot in the morning while brushing their teeth and on their left foot at night while brushing their teeth. PE skill practices consisted of tasks practiced in PE lessons that they had to practice for PE homework (e.g., throwing and catching a ball). An example of PE homework combining skill practice and parental involvement is teaching the correct performance of squats to a family member. Involving the students in planning their PE homework was sometimes part of the PE lessons' "cooling-down" session. Often, the students could choose the scale or complexity of the homework themselves and they had an influence on the activity. Improving the girls' autonomy and self-determination was the main goal in involving them in planning, choosing the scale and deciding on the amount of $\mathrm{PE}$ homework (Deci \& Ryan, 2000). Girls participated in their PE homework assignments actively, $89.7 \%$ of the girls always completed their PE homework (Kääpä et al., 2017).

\subsection{Self-Reported Data}

The students' self-reported PA was assessed using a structured diary questionnaire. The aim was to identify the frequency and type of PA that girls engaged in. The diary questionnaire consisted of categorized structures where students marked their activity frequency, level of self-initiated PA, organized sport activities, occupational activities and PE homework in which they participated within the study week. In addition, they estimated the time spent on PE homework. In this study, only self-reported PE homework reports were used. Girls this age are expected to be able to fill out this kind of structured diary that does not require a lot of creativity or writing. Self-reported data supplements the objectively measured data identifying the context of physical activity.

\subsection{Accelerometer Data}

A tri-axial accelerometer, UKK RM42 (UKK-Institute, Tampere, Finland), was selected because of its small-sized and light monitor. It can easily be worn for 24 hours a day and can collect and store data over the course of a week without 
needing to be charged. These accelerometers measure accurate information concerning the duration, intensity and pattern of PA and inactive periods, posture and postural changes and the number of total and running steps and enable the comparison of accelerometer results between different studies also in adolescents (Aittasalo et al., 2015). The ability of accelerometers to also record incidental PA is important, as this might be difficult to recall in self-reports, especially for children and adolescents. The accurate information on the metabolic equivalent (MET)-values of PA levels broadens the results from the pedometer' step counts (Vähä-Ypyä et al., 2015a, 2015b). The time spent standing still, sitting and lying, PA levels and the number of daily steps and running step were categorized separately. The total number of steps includes walking and running steps. Using both types of steps along with the MET values adds variety and reliability to the results.

\subsection{Procedures}

The accelerometer- and diary-based measurements were implemented in November 2016, 3 months following the beginning of the semester, meaning that several PE homework assignments had already been completed. The teacher delivered the devices during PE lessons and instructed the girls to wear the flexible (elasticated) belt with the accelerometer around their waist, placing the monitor on the right hip. The teacher gave oral instructions, and written instructions were attached to the diary questionnaire, which was delivered during the same lesson. The girls were instructed to wear the belt for seven consecutive days during their waking hours, apart from during water-based activities such as showering or swimming. The girls started the monitoring straight away and tested the accelerometers; if a malfunction was detected, the device was replaced immediately.

The girls returned the accelerometers and their self-report diaries a week later, during their following PE lesson, fulfilling instructed seven consecutive days requirement. To obtain a comprehensive overview, only the data from the participants who used the accelerometer for at least 4 days during the week and at least 10 hours each day were accepted for the study, and the data were analysed in 6-second epochs (Troiano et al., 2008). In studies with large sample, reliability can be achieved with 3 days of recording. Studies with smaller sample sizes like this, it is recommended to measure a greater number of days to improve measurement precision (Mattocks et al., 2008). Monitoring is also recommended to be performed over an entire day (Trost et al., 2000). The average measurement time was 14 hours 30 minutes per day; the minimum time was 12 hours $8 \mathrm{mi}$ nutes, while the maximum was 19 hours 47 minutes. PE homework was given when the group had their PE lesson; the time period for completing the assigned task was a week. PE homework assignments could be performed at any time during girls' leisure time, on account of this, the weekdays or weekends were not separated. 


\subsection{Analysis}

The tri-axial acceleration data, collected at a $100 \mathrm{~Hz}$ sample rate in raw mode (in g-units), were uploaded and stored, and a statistician from the UKK -institute transferred the data into Excel spreadsheet for further analysis. The collected data were analysed in 6-second epochs and the mean amplitude deviation (MAD) of the resultant acceleration signal was calculated for each epoch (Vähä-Ypyä et al., 2015b). Further, the measured MAD values were converted to MET values in a validated way (Vähä-Ypyä et al., 2015a). MET values were used to categorize PA into different intensity levels: Light PA was defined as activity corresponding to 1.5 - 2.9 METs, moderate activity as 3.0 - 6.0 METs and vigorous activity was more than 6 MET. Body posture was classified as standing, sitting or lying for epochs of low movement intensity $(<1.5 \mathrm{MET})$. The classifications were based on the Angle for Posture Estimation (APE) algorithm, which compares the accelerometer orientation in relation to an identified upright position at the end of each 6-second epoch (Vähä-Ypyä et al., 2018).

The analyses were implemented using SPSS software. The recorded PA levels and sedentary time of each girl from the measurement days were compared. Means and standard deviations in light, moderate, vigorous and MVPA MET values, along with standing and sedentary behaviour (i.e., sitting and lying) were analysed using analysis of variance (ANOVA) and Tamhane's post-hoc test. The MET values were smoothed by calculating a 1-minute exponential moving average for each epoch; the peak hourly MET value was analysed from the smoothed MET values. In addition, the mean values and standard deviations from the number of average total and running steps per day of the girls from the 7th, 8th and 9th grades were compared by means of ANOVA and Tamhane's post-hoc test. An ANOVA and Tamhane's post-hoc test were used to compare the 7th, 8th and 9th graders in terms of their self-reported data on the frequency and time spent doing their PE homework. The girls were further divided into $2 \mathrm{PE}$ homework groups: Those who did not do PE homework at all or did it only once a week and those who did it at least twice a week. Independent-sample T-tests were used to compare two groups' daily running and total steps with the objectively measured PA levels. For the independent-samples t-tests, Cohen's $d$ was determined by calculating the mean difference between the two groups and then dividing the result by the pooled standard deviation. Cohen's $d$ is the appropriate effect -size measure when 2 groups have similar standard deviations and are of similar size, as in these data. The significance level was set at $p<0.05$.

\section{Results}

\subsection{Physical Activity Levels}

The participants' objectively measured and combined light, moderate and vigorous average PA time of the participants was 4 hours 18 minutes (SD \pm 1 hours 6 minutes). The light PA coverage of 3 hours 8 minutes ( \pm 40 minutes) was transcendent compared to a moderate-to-vigorous coverage of 1 hour 2 minutes 
( \pm 20 minutes) and 8 minutes ( \pm 6 minutes) of vigorous PA per day (Table 1 ). The average measurement time per day was comprehensive, 14 hours $30 \mathrm{mi}$ nutes, and the average sedentary time was 7 hours 37 minutes $( \pm 1$ hour $52 \mathrm{mi}$ nutes), representing $52 \%$ of the total measurement time. The participants spent an average of 2 hours 41 minutes ( \pm 55 minutes) standing still, 6 hours $29 \mathrm{mi}$ nutes ( \pm 1 hour 5 minutes) sitting and 1 hour 8 minutes ( \pm 1 hour 5 minutes) lying down on each measurement day.

The 7th graders recorded greater levels of daily light PA than those from other grades. The 7th grade girls recorded an average daily light PA time of 3 hours 28 minutes ( \pm 32 minutes); this is 34 minutes more than the girls from 8 th grade ( $p$ $=0.000)$ and 30 minutes more than the girls from the 9th grade $(p=0.000)$. Regarding daily moderate PA, there was a significant difference between the girls from the 7 th and 8 th grades $(p=0.017)$, with a 6 -minute time differential benefitting the 8 th graders. The half of the girls from the 8 th grade reached the Finnish 60-minute PA recommendation; 38\% of all girls met the recommended levels of PA. For the 7 th grade girls, 35\% met the recommendations, while $28 \%$ of the 9 th grade girls reached the 60-minute PA recommendations every day.

The 9th grade girls spent more time standing than others. There was a significant difference in time spent standing between the girls from the 7th and 9th grades $(p=0.038)$, with a 12 -minute differential between these grades.

Regarding sedentary behaviour (i.e., sitting and lying), the girls from the 8 th

Table 1. Participants' daily average time (hours and minutes) spent in different physical activity (PA) levels, including combined level of moderate and vigorous physical activity (MVPA), by grades (mean, std. deviation, ANOVA $p$-value and Tamhane's post-hoc test).

\begin{tabular}{|c|c|c|c|c|c|c|c|c|}
\hline & $\begin{array}{l}\text { 7th grade } \\
\text { (190 days) }\end{array}$ & $\begin{array}{l}\text { 8th grade } \\
\text { (152 days) }\end{array}$ & $\begin{array}{l}\text { 9th grade } \\
\text { (171 days) }\end{array}$ & $\begin{array}{c}\text { All } \\
\text { (513 days) }\end{array}$ & All & & Post-hoc & \\
\hline & $\begin{array}{c}\text { Mean } \\
(\mathrm{SD})\end{array}$ & $\begin{array}{c}\text { Mean } \\
(\mathrm{SD})\end{array}$ & $\begin{array}{c}\text { Mean } \\
(\mathrm{SD})\end{array}$ & $\begin{array}{c}\text { Mean } \\
(\mathrm{SD})\end{array}$ & ANOVA $p$-value & $7-8$ th grade & 7-9th grade & 8-9th grade \\
\hline Light PA (1.5 - 2.9 MET) & $\begin{array}{c}3: 28 \\
(0: 32)\end{array}$ & $\begin{array}{c}2: 54 \\
(0: 36)\end{array}$ & $\begin{array}{c}2: 58 \\
(0: 42)\end{array}$ & $\begin{array}{c}3: 08 \\
(0: 40)\end{array}$ & 0.000 & 0.000 & 0.000 & 0.834 \\
\hline Moderate PA (3 - 6 MET) & $\begin{array}{c}0: 59 \\
(0: 16)\end{array}$ & $\begin{array}{c}1: 05 \\
(0: 23)\end{array}$ & $\begin{array}{c}1: 03 \\
(0: 21)\end{array}$ & $\begin{array}{c}1: 02 \\
(0: 20)\end{array}$ & 0.016 & 0.016 & 0.193 & 0.656 \\
\hline Vigorous PA (over 6 MET) & $\begin{array}{c}0: 08 \\
(0: 07)\end{array}$ & $\begin{array}{c}0: 09 \\
(0: 06)\end{array}$ & $\begin{array}{c}0: 08 \\
(0: 06)\end{array}$ & $\begin{array}{c}0: 08 \\
(0: 06)\end{array}$ & 0.110 & 0.317 & 0.937 & 0.098 \\
\hline MVPA & $\begin{array}{c}1: 08 \\
(0: 40)\end{array}$ & $\begin{array}{c}1: 15 \\
(0: 43)\end{array}$ & $\begin{array}{c}1: 11 \\
(0: 40)\end{array}$ & $\begin{array}{c}1: 11 \\
(0: 41)\end{array}$ & 0.283 & 0.315 & 0.864 & 0.755 \\
\hline Time spent standing & $\begin{array}{c}2: 36 \\
(0: 47)\end{array}$ & $\begin{array}{c}2: 38 \\
(1: 02)\end{array}$ & $\begin{array}{c}2: 50 \\
(0: 57)\end{array}$ & $\begin{array}{c}2: 41 \\
(0: 55)\end{array}$ & 0.041 & 0.915 & 0.030 & 0.287 \\
\hline Time spent sitting & $\begin{array}{c}6: 30 \\
(1: 05)\end{array}$ & $\begin{array}{c}6: 31 \\
(1: 07)\end{array}$ & $\begin{array}{c}6: 25 \\
(1: 04)\end{array}$ & $\begin{array}{c}6: 29 \\
(1: 05)\end{array}$ & 0.667 & 10.000 & 0.782 & 0.864 \\
\hline Time spent lying & $\begin{array}{c}1: 19 \\
(1: 13)\end{array}$ & $\begin{array}{c}0: 41 \\
(0: 35)\end{array}$ & $\begin{array}{c}1: 20 \\
(1: 08)\end{array}$ & $\begin{array}{l}1: 08 \\
(1: 05)\end{array}$ & 0.000 & 0.000 & 10.000 & 0.000 \\
\hline $\begin{array}{l}\text { Total sedentary } \\
\text { (sitting and lying) }\end{array}$ & $\begin{array}{c}7: 51 \\
(2: 01)\end{array}$ & $\begin{array}{c}7: 11 \\
(1: 18)\end{array}$ & $\begin{array}{c}7: 45 \\
(2: 02)\end{array}$ & $\begin{array}{c}7: 37 \\
(1: 52)\end{array}$ & 0.003 & 0.001 & 0.970 & 0.008 \\
\hline
\end{tabular}


grade recorded the shortest time. The time spent sedentarily by the 7th grade girls' ( 7 hours 50 minutes) was 38 minutes more than that spent by the girls in 8th grade ( 7 hours 12 minutes) $(p=0.002)$. Moreover, the girls in the 9th grade recorded a sedentary time of 33 minutes more than that of the girls in the 8th grade $(p=0.012)$. There was a significant difference in time spent lying down: The 8th graders spent 38 minutes less lying down than the 7 th graders ( $p=$ $0.000)$ and 33 minutes less than the grade 9th graders $(p=0.000)$.

\subsection{Steps per Day}

The girls averaged 8535 steps per day (Table 2), and the average number of running steps per measurement day was 730 . The number of total steps per day varied from a minimum of 4645 steps to a maximum of 14,089 steps. One-third (32\%) of the girls reached the average 10,000-step recommendation per day (Tudor-Locke et al., 2011; Adams, Johnson, \& Tudor-Locke, 2013). The differences between the girls from the different grades were prominent, especially in terms of running steps. The average daily running steps recorded for the 9th grade girls was the lowest (547) among the grades; the 7th grade girls recorded an average of 843 daily running steps $(p=0.000)$, while the 8 th grade girls recorded an average of 796 daily running steps $(p=0.000)$. The girls from 8 th grade recorded the highest number of total steps (9036), and over $44 \%$ of them reached the average recommendation of 10,000 steps. The girls from the 7 th grade averaged 8054 steps. The difference in the total number of steps between the 7 th and 8 th graders was almost $1000(982)$ steps $(p=0.001)$.

\subsection{Self-Reported PE Homework}

The 7th and 8th graders did their PE homework more than twice a week on average, 7th grade girls' homework frequency was $2.17 \pm 1.81$ and 8th grade girls' $2.12 \pm 1.66$ occasions per week. Meanwhile, the 9th graders reported a frequency of $1.5 \pm 1.01$ occasions a week (Table 3). PE homework added on average 34 minutes active time to the girls' week. The girls from 8th grade spent an average of 51 minutes per week on PE homework, while the girls from 7th grade spent 20 minutes and the girls from 9th grade spent 32 minutes. The difference between the girls from the 7th and 8th grades was significant $(p=0.027)$ in terms of total time spent on PE homework per week.

Table 2. Average total steps and running steps per day by grade (mean, std. deviation, ANOVA p value with Tamhane's post-hoc test).

\begin{tabular}{|c|c|c|c|c|c|c|c|c|}
\hline & $\begin{array}{l}7 \text { th grade } \\
(n=190)\end{array}$ & $\begin{array}{l}\text { 8th grade } \\
(n=152)\end{array}$ & $\begin{array}{l}\text { 9th grade } \\
(n=171)\end{array}$ & $\begin{array}{c}\text { All } \\
(n=513)\end{array}$ & ANOVA & Post-hoc & & \\
\hline & $\begin{array}{c}\text { Mean } \\
(\mathrm{SD})\end{array}$ & $\begin{array}{c}\text { Mean } \\
(\mathrm{SD})\end{array}$ & $\begin{array}{c}\text { Mean } \\
(\mathrm{SD})\end{array}$ & $\begin{array}{c}\text { Mean } \\
(\mathrm{SD})\end{array}$ & $p$ value & 7 - 8th grade & 7 - 9th grade & 8 - 9th grade \\
\hline Total steps & $\begin{array}{c}8054 \\
(2156)\end{array}$ & $\begin{array}{c}9036 \\
(2618)\end{array}$ & $\begin{array}{c}8625 \\
(2421)\end{array}$ & $\begin{array}{c}8535 \\
(2418)\end{array}$ & 0.001 & 0.001 & 0.057 & 0.369 \\
\hline Running steps & $\begin{array}{c}843 \\
(624)\end{array}$ & $\begin{array}{c}796 \\
(529)\end{array}$ & $\begin{array}{c}547 \\
(417)\end{array}$ & $\begin{array}{c}730 \\
(549)\end{array}$ & 0.000 & 0.856 & 0.000 & 0.000 \\
\hline
\end{tabular}


Table 3. Self-reported PE homework frequency/week and minutes/student/week: Comparisons between the 7th, 8th and 9th grades using ANOVA $p$ values and Tamhane's post-hoc test.

\begin{tabular}{|c|c|c|c|c|c|c|c|c|}
\hline & $\begin{array}{c}7 \text { th grade } \\
n=28 \\
\text { Mean (SD) }\end{array}$ & $\begin{array}{c}\text { 8th grade } \\
n=26 \\
\text { Mean (SD) }\end{array}$ & $\begin{array}{c}9 \text { th grade } \\
n=27 \\
\text { Mean }(\mathrm{SD})\end{array}$ & $\begin{array}{c}\text { All } \\
n=81 \\
\text { Mean (SD) }\end{array}$ & $\begin{array}{l}\text { ANOVA } \\
p \text { value }\end{array}$ & $\begin{array}{l}\text { Post-hoc } \\
7 \text { - } 8 \text { th grade }\end{array}$ & 7 - 9th grade & 8 -9th grade \\
\hline $\begin{array}{c}\text { PE homework } \\
\text { (frequency/week) }\end{array}$ & $\begin{array}{c}2.17 \\
(1.81)\end{array}$ & $\begin{array}{c}2.12 \\
(1.66)\end{array}$ & $\begin{array}{c}1.52 \\
(1.01)\end{array}$ & $\begin{array}{c}1.94 \\
(1.55)\end{array}$ & 0.228 & 0.999 & 0.271 & 0.326 \\
\hline $\begin{array}{c}\text { PE homework } \\
\text { (minutes/student/week) }\end{array}$ & $\begin{array}{c}20 \\
(19)\end{array}$ & $\begin{array}{c}51 \\
(53)\end{array}$ & $\begin{array}{c}32 \\
(38)\end{array}$ & $\begin{array}{c}34 \\
(40)\end{array}$ & 0.017 & 0.027 & 0.415 & 0.365 \\
\hline
\end{tabular}

Those who did PE homework twice or more per week had 371 more daily running steps $(p=0.000)$ and 1067 more total daily steps $(p=0.107)$ than those who did not do homework as often (Table 4).

The difference in objectively measured average vigorous daily PA between the groups who did PE homework more often and those who did not was statistically significant $(p=0.000)$ (Table 5$)$. The differences comprised an average of 3 to 7 minutes, but the difference favoured the group who did more PE homework.

\section{Discussion}

As a part of the Physical Education Homework Study, adolescent girls' objectively measured PA and self-reported PE homework were examined. The girls were more active compared to those in other PA studies (Ruiz et al., 2011; Cohen, Ghosh-Dastidar, \& Lytle, 2014; Marques et al., 2015); 38\% of the girls reached the 60-minute MVPA recommendations (Currie et al., 2008). The PE homework comprised an average of 34 minutes of active time per week. As a whole, those who did PE homework at least twice per week were more physically active than those who did less PE homework. There was a statistically significant difference in vigorous PA and running steps between the PE homework groups.

On average, girls spent 1 hour 2 minutes daily on moderate PA (3 - 6 MET) and 8 minutes on vigorous PA (over $6 \mathrm{MET}$ ), with MVPA averaging 1 hour and 11 minutes. Comparing these results to those of a 9-country international study (Ruiz et al., 2011), the amount of MVPA was higher in this study than in others. According to Ruiz et al. (2011), European adolescent girls' (aged 12.5 - 17.5 years) MVPA was 49 minutes per day. In the study of the 9 European countries, 27.5\% of girls met the current MVPA recommendations (over 60 minutes per day). In the present study, $35 \%$ of girls from 7 th grade, $50 \%$ of girls from 8 th grade and $28 \%$ of girls from 9 th grade reached the 60 -minute recommendation, even if MVPA was on average 1 hour and 11 minutes. The differences between the grades in MVPA comprised a few minutes, but the 7th-grade girls were the most active when light, moderate and vigorous activities were compounded. Particularly with light PA, there were significant differences between the 7th graders and the other grades. The girls in this study were more active than in the study of Cohen, Ghosh-Dastidar, \& Lytle (2014) and in that of Marques et al. (2015). In the present study, the average MVPA of the 8th-grade girls was 75 
Table 4. Differences in self-reported homework frequency and daily steps and running steps by independent sample t-test.

\begin{tabular}{ccccc}
\hline & No PE homework or just once & PE homework twice or more & p value & Cohen's $d$ effect size \\
\hline Total steps & 8061 & 9128 & 0.107 & 0.465796 \\
mean (SD) & $(2321)$ & $(2260)$ & & 0.717128 \\
Running steps & 559 & 930 & 0.000 & \\
mean (SD) & $(372)$ & $(630)$ & & \\
\hline
\end{tabular}

Table 5. Differences in self-reported homework frequency and in MET-values in Light, Moderate and Vigorous activity levels by independent-sample t-test.

\begin{tabular}{|c|c|c|c|c|}
\hline & $\begin{array}{l}\text { No PE homework or just once } \\
\qquad n=238\end{array}$ & $\begin{array}{l}\text { PE homework twice or more } \\
\qquad n=248\end{array}$ & $p$ value & Cohen's $d$ effect size \\
\hline $\begin{array}{l}\text { Light PA (1.5 - } 3 \text { MET) } \\
\text { mean hour and minute }(\mathrm{SD})\end{array}$ & $3: 05(0: 39)$ & $3: 09(0: 40)$ & 0.796 & 0.101258 \\
\hline $\begin{array}{l}\text { Moderate PA (3 - } 6 \text { MET) } \\
\text { mean hour and minute (SD) }\end{array}$ & $0: 59(0: 19)$ & $1: 06(0: 20)$ & 0.341 & 0.358856 \\
\hline $\begin{array}{l}\text { Vigorous PA ( }>6 \mathrm{MET}) \\
\text { mean hour and minute }(\mathrm{SD})\end{array}$ & 0:07 (0:05) & $0: 10(0: 07)$ & 0.000 & 0.491553 \\
\hline
\end{tabular}

minutes, while in Cohen, Ghosh-Dastidar, \& Lytle (2014) study, their average was 22.2 minutes per day. The study of Marques et al. (2015) had the same continuum in their results: Girls aged between 10 and 18 recorded an average MVPA of 34 minutes per day, with sedentary time being 9 hours 8 minutes. In the present study, the average sedentary time was 7 hours 37 minutes, which is less than in other studies. Even if the MVPA in this study is higher than in others, the most revealing element remains the low time recorded for sedentary behaviour. What is noteworthy is that the 8th-grade girls recorded only 7 hours 12 minutes of sedentary time. In a study by Okely et al. (2011), which investigated 1518 adolescent girls, only $1.5 \%$ met the current PA recommendations; the girls spent less than $5 \%$ of their waking hours in MVPA and $60 \%$ spent time being sedentary. In this study, PA levels during school hours might be partly due to the policy of the school. It is mandatory to go outdoors during every recess, which means that even the most sedentary students engage in light activity during breaks when moving outside and then back to their classes for the next lesson.

According to methodology and research, there is a great range of variation in step-count guidelines for adolescents: Numbers vary from 9000 to 16,000 steps per day (Silva et al., 2015). The guidelines of Tudor-Locke et al. (2011) are well known and recommendations are directed to adolescent girls. To maintain an adolescent's health, the minimal recommendation of 60 minutes of MVPA is associated with the advocated 10,000 - 11,700 steps per day for adolescents (Tudor-Locke et al., 2011), which was reached by $31.6 \%$ of the girls in this study. The average number of steps per day was 8,535 , which was clearly less than in MacDonald et al.'s (2017) study, where the mean daily step count for adolescent girls (aged 12 to 15 ) was 10,287. In this study, the difference between the mini- 
mum of 4645 steps and the maximum of 14,089 steps was extensive, which might explain the lower number of average total steps.

On average, the frequency of the participants' PE homework was twice weekly. The time spent on PE homework varied from 20 minutes to 51 minutes among the different grades. The PE homework added averaging 34 minutes active time per week to the girls' after-school hours. PE homework might lower the accumulation of sedentary time throughout the afternoon by turning sedentary behaviour into more active behaviour. Moreover, some PE homework assignments required activating other persons, preferably family members. Getting parents to participate in PE homework gives them an opportunity to familiarize themselves with the content and tasks of PE (Williams \& Hannon, 2013). Parents' perceptions of PE can be sometimes outdated; thus, PE homework could provide them an overview of the current contents of PE. In addition, PE skills-practice may have been extended during after-school hours through PE homework (Gabbei \& Hamrick, 2001; Williams \& Hannon, 2013). PE homework is also valued in terms of involving students in planning, increasing their autonomy and increasing positive PA experiences (Deci \& Ryan, 2000). The study of Behrens et al. (2015), found that the teacher's supportive interaction with participants appear to be important aspect in generating an increase in PA. In their study, when teachers promoted PA, a positive relationship with MVPA was noted (Behrens et al., 2015). If the teacher's interactions and promotions can reach students in daily life (e.g., in the form of PE homework), it could increase their PA levels.

\section{Strengths and Limitations}

The strength of this study is the combined use of an objective assessment tool and a self-reported diary questionnaire. The use of accelerometers increases the verifiability of high-quality objective data concerning the quantity and type of PA being performed. Previous studies have confirmed that the accelerometer records all ambulatory activity and that accelerometers are reliable in assessing gait parameters in children and adolescents (Ekelund, Tomkinson, \& Armstrong, 2011). For example, it is more reliable to make conclusions about the predictors and health impacts of intensity-specific PA using accelerometer methods (Aittasalo et al., 2015; Brandes et al., 2006). However, self-reported PA data provide a source of information that cannot be reached by accelerometers. On the other hand, the outcome from self-reported diaries might have been affected by biases such as problems with recall, social desirability, over-reporting of frequencies or over-reporting of time spent doing PE homework. A combination of contextual self-reported data and accelerometer-assessed PA is a desirable surveillance mechanism for collecting data concerning adolescents' PA during after-school hours; these sources allow researchers to provide meaningful findings.

The classification used in this study was the APE algorithm, which compares the accelerometer orientation in relation to the identified upright position at the 
end of each 6-second epoch (Vähä-Ypyä et al., 2018). This 6-second epoch calculates more moving data compared to, for example, values measured at the end of each 1-minute epoch. In comparison with other studies, this is something to be considered. The excitement of participating in the study and wearing the accelerometer might add to the girls' PA. In this study, the predicted decline in PA did not occur: The 8th grade girls' moderate PA and MVPA were higher than the PA of girls in the other grades. Comparing the PA research results from Finland to other countries is tough to make as Finland has different approach to PA during school breaks.

Comparing those who did more PE homework with those who did less requires addressing. Those who participated more in PE homework might be more active and more physically competent in the first place. However, PE homework added PA time, at least a small amount, to those who did more homework and to those who did them less.

The small sample could be a limitation and might preclude the detection of significance; however, this selected sample only contained girls from one lower secondary school in Finland. The question of transferability regarding all aspects is relevant. In Finland, schools and PE are quite similar nationwide. In addition, in the Western world, PE and teaching styles are comparable. As such, the replication of the study is possible in other schools. There were no withdrawals or dropouts during the study. This could be due to the school structure and the influence schools and teachers have on girls of this age (Kohl II \& Cook, 2013).

Studies, in which the students' own teacher conducts the research, imply both advantages and disadvantages. It is possible that granting the consent to participate in a study leads to heightened awareness of targeted behaviours (Beets et al., 2009). Students might also exaggerate their PA behaviour in diaries, with the desire to impress their PE teacher. However, a familiar and confidential relationship between the teacher/researcher and the participants might encourage students to take the study seriously.

\section{Conclusion}

Promoting a physically active lifestyle requires reaching beyond the PE lessons. In this study, PE homework provided an opportunity to embed active assignments into the adolescent girls' daily lives replacing sedentary activities. In addition, homework requirements were used to engage families, add knowledge about the content of the PE targets and increase the time spent practicing various skills. Referring to the results of this study, adding active PE homework to the content of PE is recommended. Future studies should target the additional facilitators of active PE assignments to more thoroughly understand the role of PE homework.

This study aimed to determine the influence of organizational and pedagogical changes in school by using PE homework as a tool to influence the PA of adolescent girls. Increasing PA outside of PE has implications also for public 
health policies, the makers of which could participate in the discussion regarding the use of this practice on a wider scale. Educational policy-makers and school administrators can use these findings to guide curriculum planning and development, as schools are the focal point for interventions designed to incorporate health-enhancing PA in after-school hours.

\section{Acknowledgements}

We would like to thank Mr. Pertti Matilainen for providing valuable statistical help with the data.

\section{Conflicts of Interest}

The authors declare no conflicts of interest with respect to the research, authorship, and/or publication of this article.

\section{References}

Adams, M. A., Johnson, W. D., \& Tudor-Locke, C. (2013). Steps/Day Translation of the Moderate-to-Vigorous Physical Activity Guideline for Children and Adolescents. International Journal of Behavioral Nutrition and Physical Activity, 10, Article No. 49. https://doi.org/10.1186/1479-5868-10-49

Aelterman, N., Vansteenkiste, M., Van Keer, H., Van den Berghe, L., De Meyer, J., \& Haerens, L. (2012). Students' Objectively Measured Physical Activity Levels and Engagement as a Function of Between-Classes and Between-Student Differences in Motivation toward Physical Education. Journal of Sport \& Exercise Psychology, 34, 457-480. https://doi.org/10.1123/jsep.34.4.457

Aittasalo, M., Vähä-Ypyä, H., Vasankari, T., Husu, P., Jussila, A. M., \& Sievänen, H. (2015). Mean Amplitude Deviation Calculated from Raw Acceleration Data: A Novel Method for Classifying the Intensity of Adolescents' Physical Activity Irrespective of Accelerometer Brand. BMC Sports Science, Medicine \& Rehabilitation, 7, Article No. 18. https://doi.org/10.1186/s13102-015-0010-0

Atkin, A. J., Gorely, T., Biddle, S. J. H., Marshall, S. J., \& Cameron, N. (2008). Critical Hours: Physical Activity and Sedentary Behaviour of Adolescents after School. Pediatric Exercise Science, 20, 446-456. https://doi.org/10.1123/pes.20.4.446

Beets, M. W., Beighle, A., Erwin, H. E., \& Huberty, J. L. (2009). After-School Program Impact on Physical Activity and Fitness. American Journal of Preventive Medicine, 36, 527-537. https://doi.org/10.1016/j.amepre.2009.01.033

Behrens, T. K., Miller, D. J., Schuna, J. M., \& Liebert, M. L. (2015). Physical Activity Intensity, Lesson Context, and Teacher Interactions during an Unstructured Afterschool Physical Activity Program. Journal of School Health, 85, 880-885.

https://doi.org/10.1111/josh.12345

Blomqvist, M., Mononen, K., Konttinen, N., Koski, P., \& Kokko, S. (2015). Urheilu ja seuraharrastaminen [Participation in Sport Club Activities]. In S. Kokko, \& R. Hämylä (Eds.), Lasten ja nuorten liikuntakäyttäytyminen Suomessa; LIITU-tutkimuksen tuloksia 2014 [The Physical Activity Behaviours of Children and Adolescents in Finland: Results of the LIITU Study, 2014] (Vol. 2, pp. 74-82). Helsinki, Finland: State Sport Council Publications.

Brandes, M., Zijlstra, W., Heikens, S., van Lummel, R., \& Rosenbaum, D. (2006). Accelerometery Based Assessment of Gait Parameters in Children. Gait \& Posture, 24, 482-486. 
https://doi.org/10.1016/j.gaitpost.2005.12.006

Cohen, D. A., Ghosh-Dastidar, B., \& Lytle, L. (2014). Energy Balance in Adolescent Girls: The Trial of Activity for Adolescent Girls' Cohort. Obesity, 22, 772-780. https://doi.org/10.1002/oby.20536

Currie, C., Gabhainn, S. N., Godeau, E., Roberts, C., Smith, R., Currie, D., Picket, W., Richter, M., Morgan, A., \& Barnekow, V. (Eds.) (2008). Inequalities in Young People's Health: HBSC International Report from the 2005/06 Survey. In Health Policy for Children and Adolescents (pp. 105-107). Copenhagen, Denmark: WHO Regional Office for Europe.

Deci, E. L., \& Ryan, R. M. (2000). The "What" and "Why" of Goal Pursuits: Human Needs and the Self-Determination of Behaviour. Psychological Inquiry, 11, 227-268. https://doi.org/10.1207/S15327965PLI1104_01

Ekelund, U., Luan, J., Sherar, L. B., Eslinger, D. W., Griew, P., \& Cooper, A. (2012). Association of Moderate to Vigorous Physical Activity and Sedentary Time with Cardiometabolic Risk Factors in Children and Adolescents. JAMA, 307, 704-712. https://doi.org/10.1001/jama.2012.156

Ekelund, U., Tomkinson, G. R., \& Armstrong, N. (2011). What Proportion of Youth Are Physically Active? Measurement Issues, Levels and Recent Time Trends. British Journal of Sports Medicine, 45, 859-865. https://doi.org/10.1136/bjsports-2011-090190

Fairclough, S., \& Stratton, G. (2005). Physical Activity Levels in Middle and High School Physical Education. Pediatric Exercise Science, 17, 217-236. https://doi.org/10.1123/pes.17.3.217

Gabbei, R., \& Hamrick, D. (2001). Using Physical Activity Homework to Meet the National Standards. Journal of Physical Education, Recreation \& Dance, 72, 21-26. https://doi.org/10.1080/07303084.2001.10605733

Haapala, H., Hirvensalo, M. H., Kulmala, J., Hakonen, H., Kankaanpää, A., Laine, K., Laakso, L., \& Tammelin, T. H. (2017). Changes in Physical Activity and Sedentary Time in the Finnish Schools on the Move Program: A Quasi-Experimental Study. Scandinavian Journal of Medicine \& Science in Sports, 27, 1442-1453. https://doi.org/10.1111/sms.12790

Husu, P., Vähä-Ypyä, H., \& Vasankari, T. (2016). Objectively Measured Sedentary Behavior and Physical Activity of Finnish 7- to 14-Year-Old Children-Associations with Perceived Health Status: A Cross-Sectional Study. BioMed Central Public Health, 16, Article No. 338. https://doi.org/10.1186/s12889-016-3006-0

Kääpä, M., Hirvensalo, M., Palomäki, S., \& Valleala, U. M. (2017). Liikuntatehtäviä kotiläksyinä: Koulun ulkopuolella tapahtuva oppiminen opetuksen tukena tyttöjen liikunnassa [Physical Active Assignments as Physical Education Homework: Adolescent Girls Learning PE Outside of the School PE Lessons]. Liikunta \& Tiede, 54, 74-82.

Kohl II, H. W., \& Cook, H. D. (Eds.) (2013). Educating the Student Body: Taking Physical Activity and Physical Education to School. Committee on Physical Activity and Physical Education in the School Environment, Food and Nutrition Board, and Institute of Medicine. Washington DC: The National Academies Press.

Kokko, S., Hämylä, R., Villberg, J., Aira, T., Tynjälä, J., Tammelin, T., Vasankari, T., \& Kannas, L. (2015). Liikunta-aktiivisuus ja ruutuaika [Physical Activity and Screen Time]. In Lasten ja nuorten liikuntakäyttäytyminen Suomessa; LIITU-tutkimuksen tuloksia 2014 [The Physical Activity Behaviours of Children and Adolescents in Finland: Results of the LIITU Study, 2014] (Vol. 2, pp. 13-20). Helsinki, Finland: State Sport Council Publications.

MacDonald, M., Fawkner, S., \& Niven, A. (2017). How Much Walking Should Be Advo- 
cated for Good Health in Adolescent Girls? Journal of Physical Activity and Health, 14, 59-66. https://doi.org/10.1123/jpah.2015-0391

Marques, A., Santos, R., Ekelund, U., \& Sardinha, L. B. (2015). Association between Physical Activity, Sedentary Time, and Healthy Fitness in Youth. Medicine \& Science in Sports \& Exercise, 47, 575-580. https://doi.org/10.1249/MSS.0000000000000426

Mattocks, C., Ness, A., Leary, S., Tilling, K., Blair, S. N., Shield, J. et al. (2008). Use of Accelerometers in a Large Field-Based Study of Children: Protocols, Design Issues, and Effects on Precision. Journal of Physical Activity \& Health, 5, S98-S111. https://doi.org/10.1123/jpah.5.s1.s98

Okely, A. D., Cotton, W. G., Lubans, D. R., Morgan, P. J., Puglisi, L., Miller, J., Wright, J., Batterham, M. J., Peralta, L. R., \& Perry, J. (2011). A School-Based Intervention to Promote Physical Activity among Adolescent Girls: Rationale, Design and Baseline Data from the Girls in Sport Group Randomised Controlled Trial. BMC Public Health, 11, Article No. 658. https://doi.org/10.1186/1471-2458-11-658

Pate, R. R., \& O'Neill, J. R. (2009). After-School Interventions to Increase Physical Activity among Youth. British Journal of Sports Medicine, 43, 14-18. https://doi.org/10.1136/bjsm.2008.055517

Perusopetuksen Opetussuunnitelman Perusteet (Finnish National Core Curriculum) (2014). Finnish National Board of Education, Regulations and Guidelines 2014. 96, 19.

Pfitzner, R., Gorzelniak, L., Heinrich, J., von Berg, A., Klümper, C., Bauer, C. P., Koletzko, S., Berdel, D., Horsch, A., \& Schulz, H. (2013). Physical Activity in German Adolescents Measured by Accelerometery and Activity Diary: Introducing a Comprehensive Approach for Data Management and Preliminary Results. PLoS ONE, 8, e65192. https://doi.org/10.1371/journal.pone.0065192

Ruiz, J. R., Ortega, F. B., Martinez-Gómez, D., Labayen, I., Moreno, L. A., De Bourdeaudhuij, I., Manios, Y. et al. (2011). Objectively Measured Physical Activity and Sedentary Time in European Adolescents. American Journal of Epidemiology, 174, 173-184. https://doi.org/10.1093/aje/kwr068

Scruggs, P. W. (2007). Middle School Physical Education Physical Activity Quantification: A Pedometer Steps/Min Guideline. Research Quarterly for Exercise and Sport, 78, 284-292. https://doi.org/10.1080/02701367.2007.10599426

Silva, M. P., Fontana, F. E., Callahan, E., Mazzardo, O., \& De Campos, W. (2015). Step-Count Guidelines for Children and Adolescents: A Systematic Review. Journal of Physical Activity and Health, 12, 1184-1191. https://doi.org/10.1123/jpah.2014-0202

Smith, M. A., \& Claxton, D. B. (2003). Using Active Homework in Physical Education. Journal of Physical Education, Recreation \& Dance, 74, 28-32. https://doi.org/10.1080/07303084.2003.10608482

Tammelin, T., \& Karvinen, J. (Eds.) (2008). Recommendations for the Physical Activity of School-Aged Children (In Finnish; Abstract in English). Ministry of Education and Young Finland Association, Helsinki: Reprotalo Lauttasaari.

Tammelin, T., Laine, K., \& Turpeinen, S. (2013). Physical Activity of School-Aged Children. LIKES-Research Reports on Sport and Health 272 (In Finnish; Abstract in English). Jyväskylä: LIKES-Foundation for Sport and Health Sciences.

Troiano, R. P., Berrigan, D., Dodd, K. W., Masse, L. C., Tilert, T., \& McDowell, M. (2008). Physical Activity in the United States Measured by Accelerometer. Medicine \& Science in Sports \& Exercise, 40, 181-188. https://doi.org/10.1249/mss.0b013e31815a51b3

Trost, S. G., Pate, R. R., Freedson, P. S., Sallis, J. F., \& Taylor, W. C. (2000). Using Objective Physical Activity Measures with Youth: How Many Days of Monitoring Are Needed? Medicine \& Science in Sports \& Exercise, 32, 426-431. 
https://doi.org/10.1097/00005768-200002000-00025

Tudor-Locke, C., Craig, C. L., Beets, M. W., Belton, S., Cardon, G. M., Hatano, Y., Lubans, D. R. et al. (2011). How Many Steps/Day Are Enough? For Children and Adolescents. International Journal of Behavioral Nutrition and Physical Activity, 8, Article No. 78. https://doi.org/10.1186/1479-5868-8-78

Vähä-Ypyä, H., Husu, P., Suni, J., Vasankari, T., \& Sievänen, H. (2018). Reliable Recognition of Lying, Sitting, and Standing with a Hip-Worn Accelerometer. Scandinavian Journal of Medicine \& Science in Sports, 28, 1092-1102. https://doi.org/10.1111/sms.13017

Vähä-Ypyä, H., Vasankari, T., Husu, P., Mänttäri, A., Vuorimaa, T., Suni, J., \& Sievänen, H. (2015a). Validation of Cut-Points for Evaluating the Intensity of Physical Activity with Accelerometery-Based Mean Amplitude Deviation (MAD). PLoS ONE, 10, e0134813. https://doi.org/10.1371/journal.pone.0134813

Vähä-Ypyä, H., Vasankari, T., Husu, P., Suni, J., \& Sievänen, H. (2015b). A Universal, Accurate Intensity-Based Classification of Different Physical Activities Using Raw Data of Accelerometer. Clinical Physiology and Functional Imaging, 35, 64-70. https://doi.org/10.1111/cpf.12127

Wickel, E. E., Issartel, J., \& Belton, S. (2013). Longitudinal Change in Active and Sedentary Behaviour during the After-School Hours. Journal of Physical Activity and Health, 10, 416-422. https://doi.org/10.1123/jpah.10.3.416

Williams, S. M., \& Hannon, J. C. (2013). Physical Education Homework That Involves the Family. Strategies, 26, 3-8. https://doi.org/10.1080/08924562.2013.779848 